\title{
Management of an Epidural Catheter Rupture: A Case Report
}

Mehdi El Samali (MD)*, Mohammed Rabi Andaloussi (MD), Amine Meskine (MD), Achraf Tahri (MD), Mustapha Bensghir (PhD), Abdelouahed Baite (PhD)

Department of Anesthesiology and Intensive care, Military Hospital Mohammed V Rabat, Faculty of Medicine and Pharmacy of Rabat, University Mohammed V Rabat, Morocco

DOI: $10.36347 /$ simcr.2020.v08i08.017

| Received: 05.08.2020 | Accepted: 12.08.2020 | Published: 30.08 .2020

*Corresponding author: Samali El Mehdi

Abstract

The placement of an epidural catheter has become increasingly used in anesthetic practice. However, this procedure is not exempt from complications. Epidural catheter rupture and retention, although uncommon and rare complications, remains an area of utmost dilemma to practitioners. Herein, we describe the occurrence of such an event where an epidural catheter was blocked from its epidural insertion and complicated by a rupture.

Keywords: Epidural catheter, fracture, complication, analgesia, anesthesia.

Copyright @ 2020: This is an open-access article distributed under the terms of the Creative Commons Attribution license which permits unrestricted use, distribution, and reproduction in any medium for non-commercial use (NonCommercial, or CC-BY-NC) provided the original author and source are credited.

\section{INTRODUCTION}

The placement of an epidural catheter has become increasingly used for analgesic or anaesthetic purposes during a number of painful surgeries and procedures. However, several complications may occur during catheter placement or removal. The difficult removal of a catheter at a distance from its placement in the epidural space is an event whose incidence is estimated to be between 1 in 20,000 and 30,000 [1].

This difficulty to removal can be sometimes complicated by a catheter rupture. We report a case where the epidural catheter was blocked from its epidural insertion and complicated by a rupture.

\section{Case Presentation}

A 28-year-old female patient (weight $80 \mathrm{Kg}$, height $1.75 \mathrm{~m}$ ), gravida 1 para 0 , American society of anesthesiologists class I, was referred for labor under epidural analgesia. The pre-anesthetic evaluation was unremarkable and the spinal processes of the lumbar spine were perfectly palpable. Under full aseptic precaution, in the sitting position, a local anaesthesia of the skin was carried out by $2 \%$ lidocaine, at the level of L2-L3 interspace. The epidural space was identified with the loss of resistance to saline technique through a midline approach, using an 18-gauge needle with tuohy needle (UNILEVER ${ }^{\circledR}$ ).
The epidural space was located $8 \mathrm{~cm}$ from the skin. The catheter was easily inserted up to $14 \mathrm{~cm}$ into the epidural space, after which the tuohy needle was removed. We decided to fix the catheter at $12 \mathrm{~cm}$ mark at the skin, so the catheter was slightly retracted by gentle traction. Unfortunately, unusual resistance was noticed during the removal. The patient was then placed in lateral decubitus in squatting position with knee touching the chest. The catheter was removed with a slight force but the catheter sheared off from almost 13 cm mark.

The neurological examination did not find any sensory deficit and the patient did not express dysesthesia or any particular complaint. We decided to perform spinal analagesia at L4-L5 interspace. Subsequently, the patient gave birth to a live male infant uneventfully. Magnetic resonance imaging was initially performed but did not show the location of the catheter tip. A lumbar Computed Tomography (CT) was performed showing a catheter fragment in the epidural space (Figure-1). Immediately, neurosurgery surgeons were informed about the event. The patient and her relatives were well informed and counseled regarding the complications. A total laminectomy was planned the next day. The catheter was confirmed to be present in the area of the left L2 -L3 facet and was subsequently removed (Figure-2). The catheter presented an intact proximal tip while the distal tip was torn (Figure-3). The procedure lasted about 1 hour. The post-operative suite was simple and the patient left the hospital on the third day without complications. 


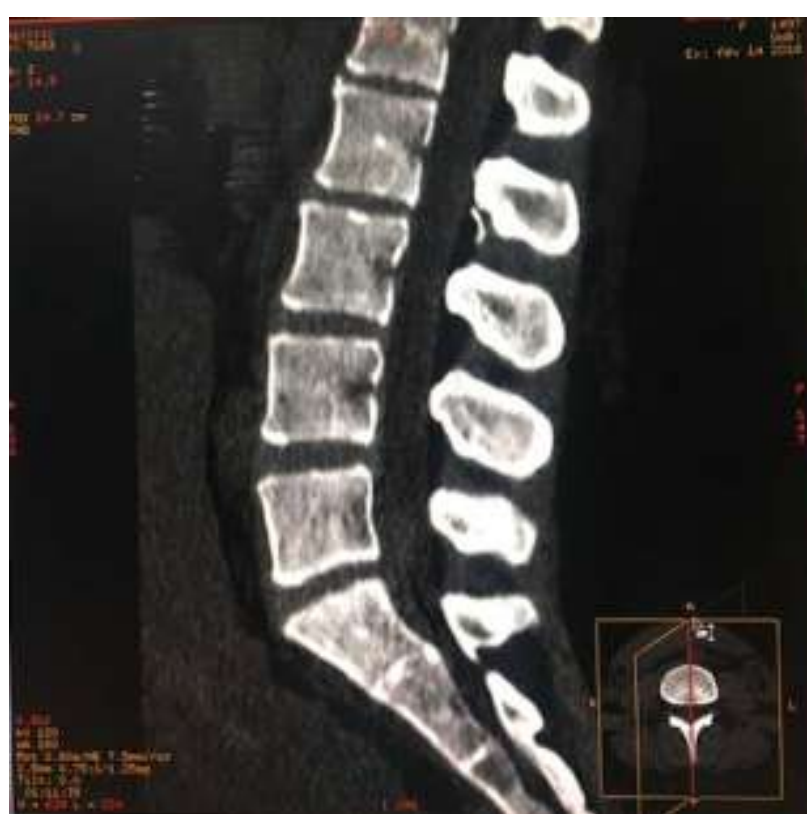

Fig-1: Lumbar sagittal CT section showing the epidural catheter as a metallically dense material between the spinous processes of $\mathrm{L} 2-\mathrm{L3}$

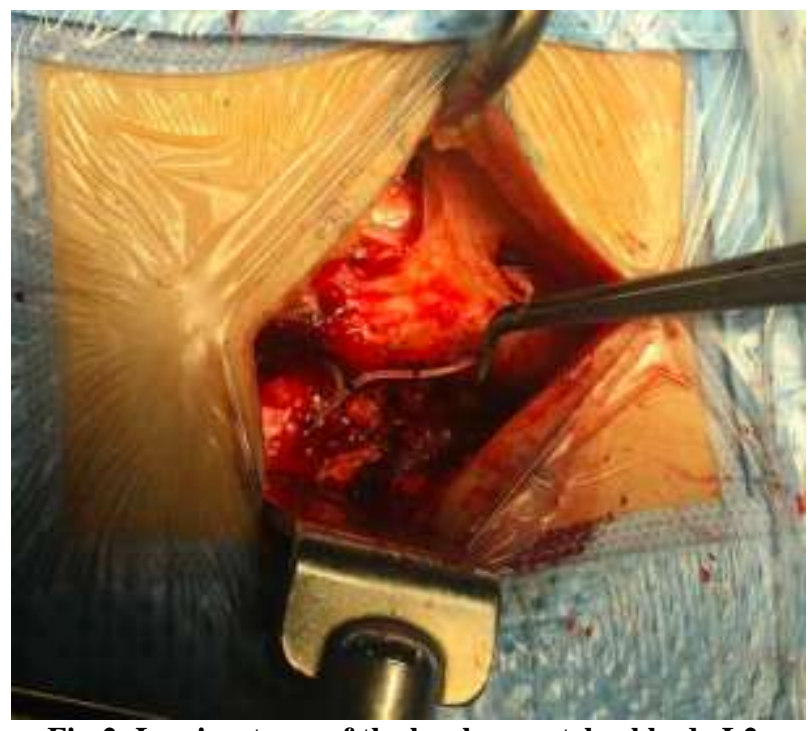

Fig-2: Laminectomy of the lumbar vertebral body L2 found the ruptured epidural catheter (white arrow)

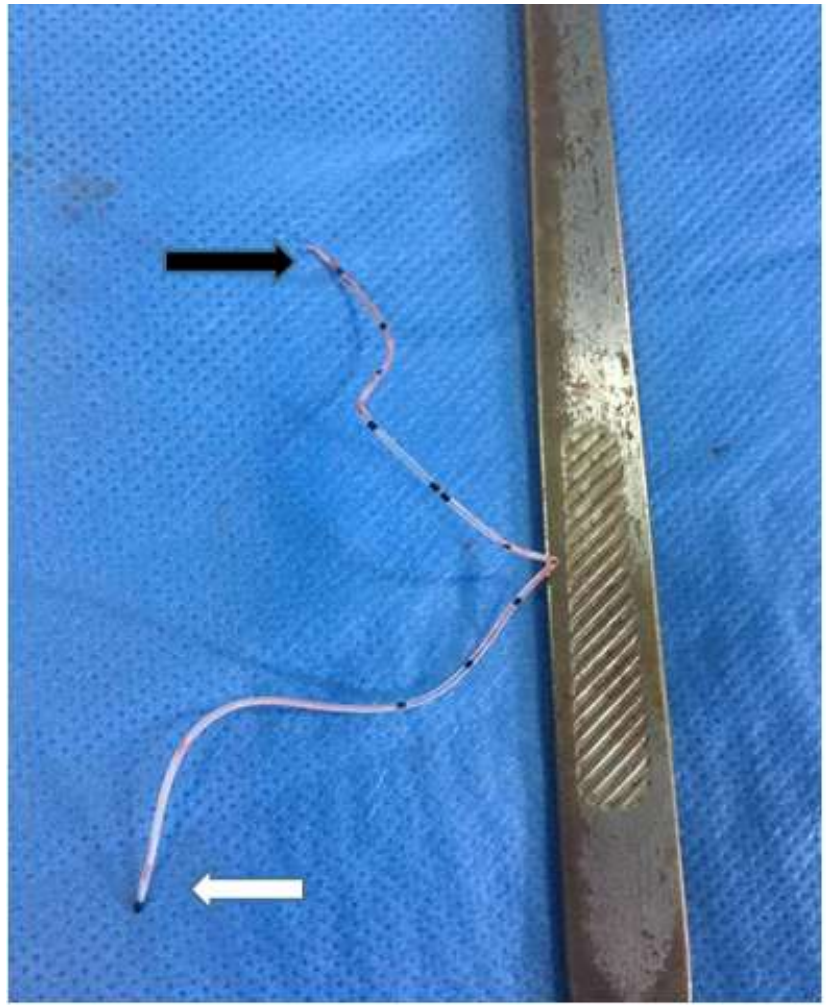

Fig-3: The proximal part of the catheter was intact (white arrow) but the distal part was torn (black arrow) without knotting or looping

\section{Discussion}

The use of an epidural catheter for labor analgesia has substantially increased in the recent years. Several epidural catheter related complications have been defined. Occlusion, knotting, curling, kinking, manufacturing defects, cutting, breakage during removal, unilateral block because of catheter position and intravascular or intrathecal placement are some of these complications [2].

Different mechanisms are invoked during a catheter rupture. The formation of a node on catheter preventing the withdrawal through the yellow ligament can be favored by a deep insertion greater than $4.5 \mathrm{~cm}$ especially at the lumbar level [3]. At the thoracic level this risk seems less likely. Compression between the spinous processes, a subperiosteal passage, strong traction with or without the use of a metal instrument during removal were also suggested mechanisms [4]. 
The mechanical characteristics of the catheters influence their rupture. Polyurethane and nylon catheters are more resistant than those in polyethylene and teflon [4]. A study carried out on the mechanical characteristics of catheters, demonstrated that polyurethane catheters are less fragile compared with nylon catheter even when traumatised. While nylon catheters can be stretched by $30 \%$ of their original length, this rate is $300 \%$ for polyurethane catheters [2].

To be able to locate the broken fragment, it has been reported that $\mathrm{CT}$ can visualize the fragments of epidural catheter remaining in place better than MRI, which appear hypodense in the $\mathrm{T} 1$, or $\mathrm{T} 2$ weighted sequences [5]. However, despite the use of all these techniques some catheters remain undetected [6].

Technical tips are described by some authors to facilitate the removal of an epidural catheter such as reposition of the patient. Moving the patient to the lateral decubitus allows the catheter to be removed with a force 2.5 times less than in the sitting position [7]. Other methods were described: continuous traction on the catheter while varying spine tilt during flexion and extension movements [1], injection of isotonic saline or air during removal, reinserting the tuohy needle with the risk of suctioning the catheter.

In case of rupture of the epidural catheter, some authors recommend surgery for symptomatic patients as soon as possible since the catheter may be hidden by fibrous tissue after 3 weeks. Surgical removal is recommended if there is evidence that the catheter fragment lies within the spinal canal [8]. If the end of the retained catheter lies outside of the skin, there exists concern for infection into the epidural space [9]. Other researchers have suggested that broken epidural catheter in pediatric patients must be removed because the risk of neurologic complications is greater than in adults [10], and surgical removal of epidural catheters than contain ferromagnetic components.

\section{Conclusion}

The breakage of an epidural catheter during insertion or removing is rare and can cause serious complications. We should strictly follow the usual guidelines for insertion and removal of epidural catheters.

Conflicts of interest: There are no conflicts of interest.

\section{Funding sources: None}

\section{REFERENCES}

1. Woehlck HJ, Bolla B. Uncoiling of wire in Arrow Flextip epidural catheter on removal. Anesthesiology. 2000; 92:907-9.

2. Ateş Y, Yücesoy CA, Unlü MA, Saygin B, Akkaş $\mathrm{N}$. The mechanical properties of intact and traumatized epidural catheters. Anesth Analg. 2000; 90:393-9.

3. Breget J-M, Fischer R, Ben Meftah R, Tabary N. Retrait impossible d'un catheter peridural. Ann Fr Anesth Reanim. 2008; 27:1016-8.

4. Nishio I, Sekiguchi M, Aoyama Y, Asano S, Ono A. Deacreased tensile strength of an epidural catheter during its removal by grasping with a hemostat. Anesth Analg. 2001; 93:210-212.

5. Staats P, Stinson S, Lee R. Lumbar stenosis complicating retained epidural catheter. Anesthesiology. 1995; 83:1115-8.

6. Sbardelotto C, Yoshimi MM, Pereira Rda R, de Castro RA. Breakage of a catheter in the epidural space Rev Bras Anestesiol. 2008; 58: 643-50.

7. Boey SK, Carrie LE. Withdrawal forces during removal of lumbar extradural catheters. $\mathrm{Br} \mathrm{J}$ Anaesth. 1994;73:833-5.

8. Mitra R, Fleischmann K. Management of the sheared epidural catheter: is surgical extraction really necessary? J Clin Anesth. 2007; 19:310-4.

9. Blanchard N, Clabeau JJ, Ossart M, Dekens J, Legars D, Tchaoussoff J. Radicular pain due to a retained fragment of epidural catheter. Anesthesiology. 1997; 87:1567-9.

10. Lenox WC, Kost-Byerly S, Shipley R, Yaster M. Pediatric caudal epidural catheter sequestration: an unusual complication. Anesthesiology. 1995; $83: 1112-4$ 